Full length article

\title{
Injunctive safety norms, young worker risk-taking behaviors, and workplace injuries
}

\author{
Simon Pek ${ }^{\mathrm{a}, *}$, Nick Turner ${ }^{\mathrm{b}}$, Sean Tucker ${ }^{\mathrm{c}}$, E. Kevin Kelloway ${ }^{\mathrm{d}}$, Jayne Morrish \\ a Beedie School of Business, Simon Fraser University, Canada \\ b Haskayne School of Business, University of Calgary, Canada \\ ${ }^{\mathrm{c}}$ Faculty of Business Administration, University of Regina, Canada \\ d Department of Psychology, Saint Mary's University, Canada \\ e Jack and Nora Walker Canadian Centre for Lifespan Development Research, Brock University, Canada
}

\section{A R T I C L E I N F O}

\section{Keywords:}

Injunctive norms

Injuries

Risk-taking

Safety

Young workers

\begin{abstract}
A B S T R A C T
Injunctive safety norms (ISNs) refer to perceptions of others' expectations of one's safety-related conduct. Drawing on a sample of Canadian young workers ( $n=11,986 ; M$ age $=17.90$ years; $55 \%$ males), we study the relationships among four sources of non-work-related (i.e., parents, siblings, friends, teachers), two sources of work-related (i.e., supervisors, co-workers) ISNs, young workers' self-reported work-related risk-taking behaviors, and workplace injuries. Structural equation modeling suggests that ISNs from parents, supervisors, and coworkers were related to less frequent work-related risk-taking behaviors, and with fewer workplace injuries via less frequent work-related risk-taking behaviors. In addition, ISNs from supervisors were directly associated with fewer workplace injuries. In contrast, ISNs from teachers and siblings were not associated with work-related risktaking behaviors, but ISNs from siblings were associated with fewer work injuries. Finally, ISNs from friends were associated with more frequent work-related risk-taking and more frequent work injuries via more frequent work-related risk-taking. This study draws attention to the relative roles of non-work sources of social influence and provides some evidence of how ISNs might be related to young workers' work-related risk-taking behaviors and their workplace injuries. It also contributes to practice by suggesting specific interventions that parents, supervisors, and co-workers could undertake to reduce young workers' work-related risk-taking and workplace injuries, namely encouraging youth to be safe at work.
\end{abstract}

\section{Introduction}

Reducing the high incidence of workplace injuries among young workers (i.e., workers 15 years and older but younger than 25 (Breslin et al., 2007; Salminen, 2004)) is an important issue for researchers, policymakers, and managers alike (Runyan et al., 2013). Young workers, particularly young males, have a significantly elevated risk of work injury (Breslin and Smith, 2005). The effects of a workplace injury can have long-lasting negative health, social, and financial effects. For example, in a U.S. sample, Dong et al. (2016) found that those who experienced a lost-time work injury reported an average \$3715 USD (in 2000 dollars) reduction in annual earnings growth over a ten-year follow-up period relative to those who had not been injured, and Galizzi and Tempesti (2015) have noted that costs of injuries have been growing over time. A growing body of research has investigated factors that predict work-related injuries among young workers, including job and workplace characteristics such as work overload and physical hazards (e.g. Breslin et al., 2007; Frone, 1998; Runyan et al., 2008), jurisdictional variation (Breslin et al., 2006), socio-demographic factors (Smith and DeJoy, 2012), and safety climate (Barling et al., 2002), which refers to "employees' perceptions about the relative importance of safe conduct in their occupational behavior" (Zohar, 1980). Yet, we still have a limited understanding of the potential relationships among a range of social influences on young workers' work-related risk-taking behaviors and injuries.

\subsection{Injunctive safety norms}

Drawing on Deutsch and Gerard's (1955) distinction among alternate forms of social influence, Cialdini et al. (1990, p. 1015) distinguished between injunctive and descriptive norms: "the injunctive meaning of norms refers to rules or beliefs as to what constitutes morally approved and disapproved conduct. In contrast to descriptive norms, which specify what is done, injunctive norms specify what ought

\footnotetext{
* Corresponding author at: Gustavson School of Business, University of Victoria, Victoria, BC, V8P 5C2, Canada.

E-mail address: spek@uvic.ca (S. Pek).
} 
to be done." Injunctive norms represent the moral rules of a group and motivate behavior through the promise of social sanction (Cialdini et al., 1991). This motivation stems from both the perceived benefits and the perceived losses of conforming to social expectations (Rimal and Real, 2003). Injunctive norms are closely related to and often included as a component of the broader construct of the subjective norm (Armitage and Conner, 2001; O'Callaghan and Nausbaum, 2006), which has been conceptualized as "the perceived social pressure to perform or not to perform [a] behavior" (Ajzen, 1991; p. 188). Numerous studies have shown that injunctive and subjective norms are associated with a wide variety of non-work-related safety behaviors such as pedestrian road crossing (Evans and Norman, 1998), bicycle helmet use (O'Callaghan and Nausbaum, 2006), and intentions to initiate alcohol, tobacco, and marijuana use (Olds et al., 2005).

Injunctive safety norms refer to the extent to which individuals perceive others' approval and expectations of safety-related behavior (Fugas et al., 2011). In the context of work-related safety behavior, examples of injunctive safety norms are a supervisor's communication of expectations of safety behavior (Zohar and Luria, 2003) or encouragement by one co-worker to another to comply with specific safety rules (Tucker et al., 2008). In contrast, an example of a descriptive safety norm is a parent modeling safety behaviors such as wearing protective equipment (Westaby and Lowe, 2005). Research into the predictive power of social influence in general, and injunctive safety norms in particular, on young worker risk-taking behavior and workplace injuries is scarce. The only existing study on the topic that we are aware of (Westaby and Lowe, 2005) investigated the relationships among perceived supervisory influence (an injunctive norm), parental risk-taking (a descriptive norm), and co-worker risk-taking (a descriptive norm) on young workers' risk-taking orientation, finding that all three of those social influences were related to lower workrelated risk-taking. Given the benefits of studying multiple sources of injunctive norms for understanding why individuals engage in specific behaviors (Neighbors et al., 2008), our study builds on this work by exploring the relationships among a wider range of sources of injunctive safety norms on young workers' risk-taking behavior and workplace injuries.

\subsection{Sources of injunctive safety norms and work-related risk-Taking behavior}

\subsubsection{Parents}

Parents can influence adolescents' work (Westaby and Lowe, 2005) and non-work (Steinberg, 2001) risk-taking behavior. Not surprisingly, many parents are involved with and concerned about their children's employment (Howe and Strauss, 2007) and job-related safety (Runyan et al., 2009), act as source for information about workplace safety (Breslin et al., 2011), and provide advice when their children express concerns about work hazards (Runyan et al., 2011). A study of child safety on family farms found that parents said they use both descriptive and injunctive norms to shape their children's safety behaviors (Neufeld et al., 2002). Research conducted in non-work contexts (e.g., home, school) shows that parental expectations are related to a range of adolescent risk-taking behaviors (Elek et al., 2006; Morrongiello et al., 2008; Simons-Morton et al., 2011; Voisine et al., 2008). For instance, Gray and Steinberg (1999) found that a parenting style characterized by the consistent establishment and enforcement of guidelines, limits, and developmentally-appropriate expectations is an important deterrent against problem behaviors such as delinquency. Based on this prior research, we hypothesize:

Hypothesis 1. Parents' injunctive safety norms will be inversely related to young workers' work-related risk-taking behaviors.

\subsubsection{Siblings}

Siblings have also been found to influence adolescent behavior in general (Lamb and Sutton-Smith, 2014) and non-work risk-taking in particular (Leonardi-Bee et al., 2011). Morrongiello and Bradley (1997) studied older siblings' influences on children's evaluations of behaving in ways that pose risks to their physical safety. These authors found that in three hypothetical play situations, older siblings influenced the safety-related behaviors of their younger siblings in both positive and negative ways: some siblings who initially made less risky choices were persuaded to make riskier choices, while others switched from risky to less risky choices. We are aware of no research that has examined the extent to which siblings influence such behaviors in work settings. Prior research thus points to both the positive and negative relationships that siblings can have with adolescents' risk-taking behaviors. This suggests that siblings' encouragement to behave safely at work could persuade adolescents to behave safely at work. We therefore hypothesize:

Hypothesis 2. Siblings' injunctive safety norms will be inversely related to young workers' work-related risk-taking behaviors.

\subsubsection{Friends}

Friends are an important influence on the development and behavior of adolescents (Savin-Williams and Berndt, 1990), and in many cases have more influence on adolescents than adolescents' parents do (Harris, 1995). For example, Urberg et al. (1997) found that influence from close friends and members of friendship groups predicted adolescents' transitions into alcohol and cigarette use. Brown et al. (1986) found that youth reporting higher levels of explicit peer pressure from their friends were more likely to engage in behaviors such as substance abuse and theft. Similarly, Raffaelli and Crockett (2003) found that adolescents' reports of peer pressure from friends were associated with increased sexual risk-taking years later. Finally, Christensen and Morrongiello (1997) studied peer influences on children's evaluations of threats to physical safety and found that significant numbers of participating children were persuaded by their friends to make riskier choices in two out of three hypothetical play scenarios. Prior work thus suggests that friends' encouragement to act in an unsafe manner may be related to youth behaving in an unsafe manner. While there is less direct evidence to date, the opposite relationship is also possible: that encouragement to behave in a safe manner may be related to youth acting in a safe manner. Given the potential influence of friends on risktaking, Miller et al. (2007) identify peer groups as an effective mechanism for increasing adolescents' awareness of workplace safety. We therefore hypothesize:

Hypothesis 3. Friends' injunctive safety norms will be inversely related to young workers' work-related risk-taking behaviors.

\subsubsection{Teachers}

Teachers have an important role in adolescent socialization (Ryan et al., 1994). Some work-related safety educational programs delivered by teachers, which involve prescribing ways of behaving in a workplace, show increases in student knowledge and critical thinking skills about safety (Linker et al., 2005). Further, in a program focusing on farm-related safety behavior involving students who worked on farms, Reed et al. (2003) found that three-quarters of students who participated in the program made positive changes to work-related behavior as a result of the teacher-driven program. The influence of teachers extends to risky behaviors beyond the workplace. For instance, Tyler et al. (2006) found that, in a sample of 16-to-18 year-olds, the more teachers helped these students with personal problems and insisted on students performing to the best of their abilities, the lower the risk of alcohol misuse. Although limited, this body of work leads us to hypothesize:

Hypothesis 4. Teachers' injunctive safety norms will be inversely related to young workers' work-related risk-taking behaviors. 


\subsubsection{Supervisors}

The role of work supervisors in establishing and maintaining a safety climate that promotes safe work behavior is well established (Clarke, 2012), showing positive effects of supportive and encouraging leadership across time periods, age of samples, and styles of leadership. As examples, Parker et al. (2001) found a lagged (18-month) positive relationship between supportive supervision (i.e., a supervisor encouraging their staff to make suggestions) on self-reported safe working. In a sample of young workers, Barling et al. (2002) showed support for safety-specific transformational leadership (which embodies supervisors setting high expectations of work safety behavior among their employees) as a predictor of fewer occupational injuries via safety consciousness and safety-related events such as near-misses. Finally, Westaby and Lowe (2005) found that supervisor injunctive norms were negatively associated with young worker risk-taking. Based on this body of research, we hypothesize:

Hypothesis 5. Supervisors' injunctive safety norms will be inversely related to young workers' work-related risk-taking behaviors.

\subsubsection{Co-workers}

While the predominant focus in occupational safety research has been the influence of supervisors on frontline employee safety behavior, studies have also begun to examine the impact of co-workers (Tucker et al., 2008; Turner et al., 2010; Westaby and Lowe, 2005). In an adult sample, Fugas, Silva, and Meliá (2013) found that co-workers' descriptive safety norms helped explain the difference between groups of employees with low and moderate proactive safety behaviors. In addition, many of the items in Brondino et al. (2012) measure of coworker safety climate (e.g., "Team members remind [others of] safety equipment use") relate to setting peers' expectations of work-related safety behaviors (an injunctive norm). In that study, the authors found a positive relationship between co-worker safety climate and both safety compliance and safety participation behaviors. Other evidence suggests that perceptions of co-workers' concern for safety issues was associated with more frequent safety behaviors in the workplace (Jiang et al., 2010), and, conversely, safety-related teasing from co-workers increases the likelihood of engaging in unsafe behavior (Mullen, 2004). Based on this body of research, we hypothesize:

Hypothesis 6. Co-workers' injunctive safety norms will be inversely related to young workers' work-related risk-taking behaviors.

\subsection{Work-Related risk-taking behavior and injuries}

Young workers experience job-related physical injuries ranging in magnitude from minor scratches, cuts requiring first aid attention, and burns requiring medical attention and time off work to heal (Breslin et al., 2003). The relationship between injury experience and various employee safety behaviors has attracted much research attention. In terms of research on young workers, Westaby and Lowe (2005) found that an individual's risk-taking orientation, which includes behaviors such as taking risks to get one's work done faster, was positively associated with self-reported work injuries requiring medical attention. This finding is echoed by work on adult populations. Behaviors categorized as safety compliance (e.g., adhering to work-related safety practices) and safety participation (e.g., offering suggestions to improve safety processes) have been found to be negatively associated with injuries (Clarke, 2006), while risky and unsafe behaviors (e.g., taking short cuts, not using personal protective equipment) have been found to be positively associated with injuries (Christian et al., 2009). In their longitudinal study, Galizzi and Tempesti (2015), for instance, found that occupational injuries were positively associated with risky behaviors.

Hypothesis 7. Young workers' work-related risk-taking behavior will be positively associated with workplace injuries.

\section{Methodology}

\subsection{Study context and procedure}

Between November 2012 and December 2013 (inclusive) participants responded to a short survey prior to taking one of six on-line occupational safety tests collectively called Passport to Safety ${ }^{\text {тм }}$ (PS) (Parachute Canada, 2013). PS offers online modules that raise awareness about workplace safety and educate young people about their rights and responsibilities, hazards in the workplace, and related topics. The PS Challenge for Teens test, the most popular of the six tests (approximately $85 \%$ of all test takers complete this test), is designed for high school curricula and, at the time this research was conducted, was approved for use in high schools in four Canadian provinces: New Brunswick, Newfoundland, Nova Scotia, and Ontario. Other PS test takers typically take a test in their workplace as a part of safety training.

The voluntary survey, which appeared before the test, was meant to be completed in $30 \mathrm{~s}$ and thus contained relatively few items. The study received university ethics board approval, and data from different user surveys (from unique samples) have been reported in other publications (see Tucker et al., 2015; Turner et al., 2015; Tucker et al., 2014). Readers interested in more information on the study context may wish to consult these sources.

\subsection{Measures}

\subsubsection{Injunctive safety norms}

Participants were asked how often six individuals and/or groups of individuals encouraged them to be safe at work. These sources were "my parent(s)/guardian(s)," "my siblings," "my friends," "my teachers/ instructors," "my workplace supervisor," and "my co-workers." We used a 6-point, Likert-type scale with response choices ranging from 2 (almost never), 4 (sometimes), and 6 (almost always). We also included a does not apply category (coded as 1) in the response set to accommodate those who did not work with co-workers, were self-employed (i.e., had no supervisor), are only children (i.e., have no siblings), or otherwise had no contact with a group (e.g., parents, friends) that were listed. ${ }^{1}$ Prior to conducting the analyses, we recoded the items so that 1 corresponded to almost never, 3 to sometimes, and 5 to almost always, 2 and 4 ranged in between these anchors, and recoded the does not apply category as a missing variable. We conducted all analyses using pairwise deletion.

\subsubsection{Work-related risk-taking behavior}

Participants were asked how frequently they engaged in unsafe behavior at their main job (defined as the job they work the most hours). Due to space limitations, we used three of the highest-loading items from Tucker and Turner's (2011) safety neglect scale to measure work-related risk-taking behavior. The items we used were "take short cuts that threaten my personal safety," "stop following health and safety policies," and "ignore safety problems altogether." A five-point response scale was used with 1 corresponding to almost never, 3 to sometimes, and 5 to almost always, with 2 and 4 sitting between 1 and 3 and 3 and 5 , respectively. Cronbach's alpha for the scale was .85, indicating satisfactory internal consistency.

\footnotetext{
${ }^{1}$ For each source of injunctive safety norms, we report here the number of cases that reported "does not apply" or did not complete the value, both of which were counted as missing values: parents $(n=869,7.3 \%)$, siblings $(n=2300,19.2 \%)$, friends $(n=1657$, $13.8 \%)$, teachers $(n=1042,8.7 \%)$, co-workers $(n=835,7 \%)$, and supervisors $(n=766,6.4 \%)$
} 
Table 1

Means Standard Deviations, and Intercorrelations among Study Variables (N = 9340-11,938).

\begin{tabular}{|c|c|c|c|c|c|c|c|c|c|c|c|}
\hline Variable & $M$ & $S D$ & 1. & 2. & 3. & 4. & 5. & 6. & 7. & 8. & 9. \\
\hline 1. Sex & .55 & .50 & - & & & & & & & & \\
\hline 2. Age & 17.90 & 1.56 & -.04 & - & & & & & & & \\
\hline 3. Parents' ISN & 4.17 & 1.16 & -.05 & .04 & - & & & & & & \\
\hline 4. Siblings' ISN & 3.15 & 1.51 & $.02^{*}$ & .11 & .56 & - & & & & & \\
\hline 5. Friends' ISN & 3.09 & 1.45 & -.04 & .12 & .53 & .76 & - & & & & \\
\hline 6. Teachers' ISN & 4.09 & 1.22 & $-.02^{*}$ & .09 & .50 & .47 & .51 & - & & & \\
\hline 7. Coworkers' ISN & 4.04 & 1.14 & -.07 & .09 & .50 & .48 & .51 & .52 & - & & \\
\hline 8. Supervisors' ISN & 4.39 & 1.02 & -.04 & .07 & .49 & .38 & .38 & .49 & .72 & - & \\
\hline 9. WRTB & 1.46 & .80 & .12 & -.08 & -.11 & -.04 & -.05 & -.07 & -.13 & -.14 & $(.85)$ \\
\hline 10. Injuries & .64 & 1.11 & $.00^{\dagger}$ & -.10 & -.08 & -.09 & -.09 & -.07 & -.08 & -.08 & .18 \\
\hline
\end{tabular}

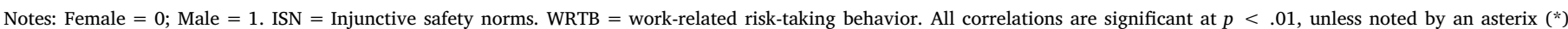
indicating $p<.05$, or a dagger $(\dagger)$ indicating $p>.05$.. The coefficient alpha for WRTB is in the diagonal. Pairwise deletion was used.

\subsubsection{Workplace injuries}

We asked respondents "how many times in the past 4 weeks have you had a 'minor' workplace injury (e.g., cut, burn, strain, sprain, etc.) at your main job?" The response options were (with coding in brackets) no (0) injuries, one (1) injury, two (2) injuries, three (3) injuries, four (4) injuries, and five (5) or more injuries.

\subsubsection{Demographic variables}

We controlled for participant sex $(0=$ female; $1=$ male $)$ and age (in years).

\subsection{Structural equation modeling}

We incorporated the seven hypotheses into a structural equation model, estimating the model using a combination of single- and multiple-indicator variables in Mplus 7.2 (Muthén and Muthén, 2010). The requirement for a short survey, coupled with our interest in multiple sources of norms, resulted in our use of single indicators for the six injunctive safety norms. Workplace injuries were also represented in the model by a single indicator. Respondents' age and sex were modeled as covariates predicting both work-related risk-taking behavior and work injuries. Finally, work-related risk-taking behavior was defined as a latent variable comprising three indicators (i.e., the three items comprising the scale).

We viewed our measure of work injuries as a count variable, estimating the model using negative binomial equations. The remaining relationships were estimated using robust maximum likelihood estimates. This form of estimation does not allow for the chi-squared-based indices of fit typically used to evaluate structural equation models. Accordingly, we rely on the Aikake Information Criterion (AIC), Bayesian Information Criterion (BIC) and sample-size adjusted BIC to compare alternate models (Vrieze, 2012). These fit indices are used to compare model fit and do not have an absolute interpretation (i.e., there is no criterion for defining good fit); however, the model with the lower information criteria values is considered to be the better fitting model.

Following accepted structural equation modeling practice, we estimated three alterative models. First, the hypothesized model (Model 1) incorporates the hypotheses outlined above and represents a mediated process whereby injunctive safety norms are related to work injuries through the mediating variable of work-related risk-taking behaviors. Second, an implicit assumption of our model is that injunctive norms from different sources will have differential relationships with workrelated risk-taking behavior. We empirically examine this procedure by contrasting the hypothesized model with a model in which the six injunctive norms were constrained to equality (Model 2). Finally, a second alternative model (Model 3) is a partially-mediated model which adds to the mediated model direct paths between the six injunctive safety norms and work injuries. As Model 2 is nested within Model 1 and Model 1 within Model 3, we used the Satorra-Bentler scaled chi-squared difference test (Satorra and Bentler, 2010) based on the likelihood statistic to assess the differences between the nested models.

Although the estimation procedures used for these data do not allow for either bootstrapping or the calculation of indirect effects, we used the procedures described by Preacher et al. (2010) to calculate the indirect effects implied by the model and the confidence intervals around the estimates. As noted by Smith (2015), the ability to estimate such indirect effects is a particular strength of structural equation modeling which is not available through other techniques such as multiple regression.

Due to the moderate to high correlations among the predictor variables ( $r s$ range from .38 to .76), we calculated variance inflation factors (VIF) for each of the predictors to determine whether multicollinearity was a concern (Hair et al., 1995). The VIF scores for the six sources of injunctive safety norms ranged between 1.53 and $2.66(M$ VIF score $=2.18$ ), are below typical VIF cut offs of 5 to 10 , and are appropriate given the size of our sample (O'Brien, 2007).

\section{Results}

Just over 45,000 individuals began the user survey prior to taking the PS test. Of this number, 11,986 indicated they were currently employed and between the age of 15 and 24 years inclusive $(M$ age $=17.90$ years, $S D=1.56 ; 55 \%$ male). Participants aged 16,17 , 18 , and 19 comprised $88.3 \%$ of the sample. Table 1 shows the descriptive statistics and correlations among the study variables. Pairwise deletion was used to handle missing data.

Table 2 shows that the hypothesized model (Model 1) provides a better overall fit to the data compared to an alternative model (Model 2 ) in which the effects of injunctive norms on work-related risk taking were constrained to equality, $\Delta \mathrm{c}^{2}(5)=172.09, p<.01$. Model 3 (i.e.,

Table 2

Model Fit Statistics.

\begin{tabular}{llll}
\hline & AIC & BIC & Adjusted BIC \\
\hline Model 1* & 77947.97 & 78096.91 & 78030.17 \\
Model 2 & 78089.45 & 78202.92 & 78152.08 \\
Model 3 & 77853.04 & 78044.53 & 77958.73 \\
Model 4 & 77855.19 & 78018.32 & 77945.23
\end{tabular}

Note: * Hypothesized model. Model 1: work-related risk-taking behavior mediates the relationship between the six injunctive safety norms and workplace injuries, controlling for age and sex. Model 2: relationship between six injunctive safety norms and workrelated risk taking are constrained to equality. Model 3: work-related risk-taking behavior and the six injunctive safety norms are directly related to workplace injuries, controlling for age and sex. Model 4: revised model - work injuries are predicted by work-related risk-taking behaviors as well as both siblings' and supervisors' injunctive safety norms, controlling for age and sex. AIC = Akaike Information Criterion; BIC = Bayesian Information Criterion; Adjusted BIC = Sample-size adjusted BIC 


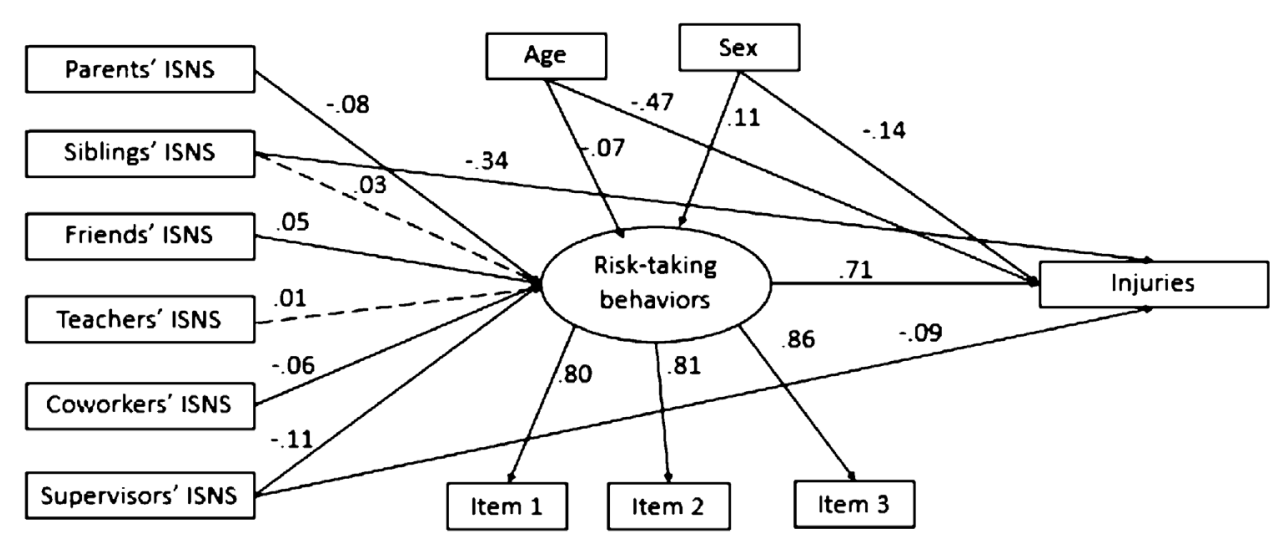

Fig. 1. Standardized parameters for the revised model (Model 4).

Note. Standardized parameter estimates are reported here. Solid lines represent statistically-significant relationships, dotted lines represent statistically nonsignificant relationships. Item $1=$ "take short cuts that threaten my personal safety". Item $2=$ "stop following health and safety policies". Item 3 = "ignore safety problems altogether". work-related risk-taking behavior and the six injunctive safety norms are directly related to workplace injuries, controlling for age and sex) provided a better fit to the data than our hypothesized mediational model, $\Delta \chi^{2}(6)=56.71, p<.01$. Inspection of the model parameters suggested that both siblings' and supervisors' injunctive safety norms predicted fewer injuries directly. We incorporated those paths into a final revised model (Model 4).

The standardized parameter estimates for the revised model (see Fig. 1) provide support for four of the seven hypotheses. Less frequent work-related risk-taking behavior was predicted by perceptions of parents' (Hypothesis 1: $\beta=-.08, p<.01$ ), supervisors' (Hypothesis 5: $\beta=-.11, p<.01$ ), and coworkers' (Hypothesis 6: $\beta=-.06$, $p<.01$ ) injunctive safety norms, and work injuries were predicted by respondents' work-related risk-taking behaviors (Hypothesis $7: \beta=.71$, $p<.001)$. As noted above, less frequent injuries were also predicted by siblings' $(\beta=-.34, \quad p<.01)$ and supervisors' $(\beta=-.09$, $p<.01$ ) injunctive norms, controlling for all other relationships in the model. Contrary to Hypothesis 3 , friends' $(\beta=.05, p<.05)$ injunctive safety norms were related to more frequent work-related risk-taking behavior. Neither siblings' $(\beta=.03, p>.05)$ nor teachers' $(\beta=.01$, $p>.05)$ injunctive safety norms made a statistically-significant contribution to predicting work-related risk-taking behaviors, resulting in a lack of support for Hypothesis 2 and Hypothesis 4, respectively. Finally, in relation to work-related risk-taking and work injuries, respectively, respondents' sex $(\beta=.11, p<.01 ; \beta=-.14, p<.01)$ and age $(\beta=-.07, p<.01 ; \beta=-.47, p<.01)$ were were significant predictors . Parents' $(\mathrm{b}=-.08 ; 95 \% \mathrm{CI}=-.11$ to -.05$)$, friends' $(\mathrm{b}=.05,95 \% \quad \mathrm{CI}=.02$ to .08$)$, coworkers' $(\mathrm{b}=-.06 ; 95 \%$ $\mathrm{CI}=-.09$ to -.02$)$ and supervisors' $(\mathrm{b}=-.11,95 \% \mathrm{CI}=-.15$ to -.09 ) injunctive safety norms all had significant indirect relationships with work injuries via work-related risk-taking behaviors.

The six injunctive safety norms collectively explained $5.2 \%$ of the variance in work-related risk-taking behavior. More specifically, and acknowledging that variance explained will be non-additive due to the correlation among the six injunctive safety norms, injunctive safety norms from work-related sources (i.e., coworkers and supervisors) alone predicted $4.7 \%$ of the variance in work-related risk taking, whereas injunctive safety norms from non-work-related sources (i.e., parents, siblings, friends, and teachers) alone explained $3.7 \%$ of the variance in work-related risk taking behavior.

\section{Discussion}

Using a large sample of young workers, we investigated the relationship between six sources of injunctive safety norms and young workers' work-related risk-taking and work injuries. Our study builds on prior work investigating the roles of different social influences on young workers' risk-taking behavior, but broadens the range of social influences considered to include injunctive safety norms from both work and non-work domains.
First, our findings support Westaby and Lowe's (2005) findings about the importance of supervisors' injunctive safety norms along with broader work on the importance of high-quality supervision and leadership on safety behaviors (Clarke, 2012). Second, our findings extend Westaby and Lowe's (2005) findings about the relationship between coworkers' descriptive norms and young workers' risk-taking behaviors by suggesting that co-workers may also influence safety through explicit encouragement in the form of injunctive safety norms. While much prior work has focused on work-related sources, less well-studied are non-work-related sources of social influence and young workers' risktaking behavior. Westaby and Lowe (2005) investigated parents' risktaking behavior, which is more closely linked to the notion of descriptive norms. Third, our results suggest that parents' injunctive norms may also make a difference in terms of reducing young workers' risk-taking behaviors. To reduce the extent to which their children neglect work safety rules and experience on-the-job injuries, parents alongside supervisors and co-workers should explicitly encourage and set expectations around safety at work. In a broader sense, our findings highlight the importance of considering parents as a potentially important source of social influence in predicting young workers' safety outcomes.

In addition to the sources of influence identified by Westaby and Lowe (2005), our study also assessed the importance of injunctive safety norms from three other non-work sources: friends, teachers, and siblings. Unexpectedly, friends' injunctive safety norms were associated with more frequent work-related risk-taking behavior and in turn more frequent work injuries. One explanation for this result may be the crosssectional nature of the data. Specifically, encouragement to be safe could have come after instances of unsafe behavior were communicated by participants to their friends. This explanation implies that increased encouragement from friends to be safe at work is a response that follows young workers sharing stories about their own unsafe work behavior. Further, we suspect this pattern was limited to friends due to two reasons: the relative ease of disclosure of unsafe behavior to friends compared to adult sources of social influence, and the relative inability of friends to sanction compared to non-work adults (e.g., parents) and those with formal authority at work (e.g., supervisors). Finally, in contrast to the substantive explanations for this counter-hypothesized finding, there is a possibility that the pattern of relationships represents a regression artifact of negative suppression (Tzelgov and Henik, 1991). That is, consistent with our hypothesis, a negative zero-order correlation exists between friends' injunctive safety norms and work-related risk-taking $(r=-.05, p<.01)$. However, the resulting beta weight for the same relationship (in the presence of the other sources of injunctive safety norms) in the structural equation model is positive ( $\beta=.05, p<.05)$, running counter to the hypothesis. This switching of signs between the zero-order relationship and in the presence of the other five social influences included in the model calls into question the stability of the findings for friends' injunctive safety norms. While suppressor effects may not be common, it is important to consider this 
possibility when models such as this comprise a range of independent albeit correlated predictors.

We were further surprised that teachers' injunctive safety norms were not related to young workers' risk-taking given the reported benefits of work safety educational programs delivered by teachers (Linker et al., 2005) and teacher-driven farm-related safety programs (Reed et al., 2003). A possible explanation for this null finding is that teachers' injunctive safety norms may only be effective when incorporated into structured education programs and, in particular, in programs in which teachers do not face time constraints and have access to high-quality resources and training (Pisaniello et al., 2013). Linker et al. (2005), for instance, argued that successful teacher-driven programs about workplace safety should be realistic, engage youths' interests, and be tailored to their specific circumstances. Webb and Ronan (2014) found that designing a natural hazard educational program in a manner that is interactive and engaging helped increase youths' knowledge and preparedness activities. In the absence of these features, teachers' injunctive safety norms may not have a meaningful relationship with young workers' safety outcomes.

Finally, siblings' injunctive safety norms were not related to young workers' risk-taking behavior but were predictive of fewer work injuries. Siblings are not proximal to one another's work contexts, as in the case of supervisors and co-workers. For example, younger siblings are not likely to be in a position of authority and may not have the ability to discuss with an older sibling how to behave at work. Further, older siblings are more likely to live on their own and thus have infrequent contact with a younger brother(s) and/or sister(s). Although siblings did not influence the work-related risk-taking behavior of participants, the direct relationship with injuries suggests that siblings may influence each other's safety outcomes, the mechanism by which remains a topic for future research.

Our two control variables (participant age and sex) were also related to work-related risk-taking behavior and work injuries. Older participants in our sample reported on average lower work-related risktaking behavior and work injuries. Younger people are generally more likely to engage in risk-taking actions across domains (Byrnes et al., 1999), and research on the relationship between age and microaccidents (the type of work injury examined in this study) shows that, among the young worker population (i.e., ages 15-24), younger workers experience more frequent microaccidents (Turner et al., 2015). It is important to remember, however, that the age range (i.e., young workers) examined here $(M=17.90$ years, $S D=1.56)$ is relatively narrow. As such, the magnitude of the parameter estimates of the agework-related risk-taking and age-work injuries relationships are likely inflated compared to if we examined the same relationships in samples with a broader age range (i.e., adult working sample ranging in age from 25 through retirement).

Our results also showed that males were more likely to engage in unsafe behavior at work than females were, which is consistent with research on work-related (Turner et al., 2015; Westaby and Lee, 2003) and non-work risk-taking (Byrnes et al., 1999). Our results regarding females' greater likelihood of injury, however, contrasts with those of official work injury statistics and studies, which more consistently show that males are more likely to be injured in the workplace than females (Breslin and Smith, 2005; WorksafeBC, 2015). We expect that our somewhat unique relationship between work injuries and sex may be due to how we measured injuries (i.e., quite minor physical injuries).

A further puzzling aspect of the results is the relatively low amount of variance in work-related risk-taking behavior explained by the six social sources of injunctive safety norms $\left(R^{2}=5.2 \%\right)$. Supplementary analysis revealed that supervisor and co-worker injunctive safety norms had a small effect size and, as a set, explained marginally more variance (4.7\%) than the non-work-related social influences (3.7\%). However, we suggest that these findings may still have important applied significance because young workers' work-related risk-taking behavior can result in serious consequences and because it may carry over into youths' future work experiences. . Finally, percentage of explained variance may be a misleading indicator when the explanatory factor cumulates in practice (Abelson, 1985), a characteristic of injunctive safety norms, which are learned and enacted over time. Inclusion of other study variables, such as individuals' risk-taking orientation (Westaby and Lowe, 2005) descriptive safety norms (Fugas et al., 2011), and environmental and job-related factors (e.g. Breslin et al., 2007) that we elaborate on in Section 4.2 could have added more nuance to our findings and ultimately explained a larger proportion of variance.

\subsection{Limitations}

This study has some important limitations. First, self-reported and retrospective data about engaging in work-related risk-taking behavior are assumed to be proxies for actual work-related risk-taking behavior. Future research should compare self-reported data with other-source measures (Fugas et al., 2011), keeping in mind the limitations inherent in employer records of safety incidents or injuries (e.g., under-reporting of near-misses and injuries). Second, although our model signals causal relationships, our cross-sectional design limits our ability to make causal inferences. Our data collection method was not conducive to contacting a large number of young workers at multiple points in time, and future research could use a longitudinal design to assess better both directionality and lagged exposure to injunctive safety norms. Longitudinal designs are the most robust design for testing mediation, as a strong mediator using cross-sectional data may not be a mediator in longitudinal analysis (Maxwell and Cole, 2007). Third, because the vast majority of respondents completed the survey in a classroom, our sample may not equally represent those young workers who did not complete high school; this is important as high school leavers report more frequent workplace injuries than do completers (Breslin, 2008). Further, it is possible that classes oriented towards practical job skills maybe more likely to offer the PS test than students in classes in academic streams. This could also affect the representativeness of our sample.

Fourth, in measuring social influences, we relied on respondents' subjective perceptions of receiving encouragement to act safely at work. It is possible that participants confounded pro-safety encouragement with, for example, respect for their relationship with the particular referent individual or group. Fifth, each source of injunctive safety norms was measured with a single item, a practice adopted by others studying social norms (Armitage and Conner, 2001). Using multiple-item scales, however, can increase reliability, particularly when measuring abstract constructs (Bergkvist and Rossiter, 2007), helping ensure content validity. While we see our use of single-item scales as a limitation (brought about by the inherent constraint of using a short survey in the study context), benefits of using single-item scales include increasing the likelihood of gaining a large sample (Fuchs and Diamantopoulos, 2009) and reducing respondents' fatigue, boredom, and frustration (Robins et al., 2001). Furthermore, while there is no consensus within the scientific community, scholars have found that some single-item scales may be as reliable as multiple-item scales (Wanous et al., 1997), particularly when constructs are unidimensional (e.g., global self-esteem (Robins et al., 2001)). Sixth, and finally, due to space limitations, we could not control for type of work or relative levels of occupational hazards among workplaces, both of which could affect our findings.

\subsection{Future research directions}

Our study is among the first to investigate the link among non-workrelated sources of injunctive norms and young workers' risk-taking behaviors. Given our unexpected findings about the influence of friends' injunctive safety norms, future research should further investigate their relationship with young workers' risk-taking behavior 
and work injuries. In comparison to other adult-aged sources of injunctive safety norms, the importance of teachers in promoting safe work behavior was trivial, potentially calling into question the source through which safety-focused school curriculum is communicated. However, as we noted earlier, an explanation for this finding may be that teachers' influence differs based on whether it is part of a structured education program or not, although our study did not enable us to control for this. We think educators and policy-makers should investigate further the linkage between specific safety-focused programs and other forms of teachers' influence on work-related risk-taking behavior to understand better which sources of injunctive and descriptive norms would be most effective at influencing behavior and ultimately injury experience.

Central to Zohar's (2010) concept of safety climate is the idea that employees look to supervisors and managers for clues about the safetyrelated work behaviors that are valued and rewarded in their organization. For instance, Zohar and Polachek (2014) found that changes to supervisors' daily communications to demonstrate a prioritization of safety resulted in changes in safety-related behaviors and safety climate. Yet it is also possible that pro-safety words (injunctive norms) that are not consistently backed up by pro-safety actions (descriptive norms) would be indicative of a weak safety climate, which in turn would have a weaker impact on safety behavior. Among studies that investigate both types of norms concurrently, albeit not in the context of work safety, some studies find that both types of norms have a similar predictive effect (e.g. Elek et al., 2006), while others that they have different predictive effects (e.g. Rimal and Real, 2003). Future research could build on our findings to explore the concurrent relationship of both types of norms and the potential interrelations among them.

Another fruitful direction for future research would be the relationship between young workers and the various sources of injunctive safety norms. For instance, the level of affective proximity (Fugas et al., 2011), frequency of interaction, and duration of the relationship (Marsden and Campbell, 1984) could moderate the relationship between perceived injunctive safety norms and work risk-taking behavior. For instance, Yagil and Luria (2010) found that the strength of social ties with co-workers may increase the saliency of safety climate on safety behavior. Considering these relationship characteristics could help develop a more nuanced understanding of the linkage between injunctive safety norms and young workers' risk-taking behavior.

Finally, scholars could investigate the effects of environment- and job-related factors on the relationship between injunctive safety norms and young worker risk-taking behaviors. These factors are wide ranging, and include working conditions, work setting, workload and perceived work overload, access to personal protective equipment and relevant training, and safety climate (Barling et al., 2002; Breslin et al., 2011, 2007; Frone, 1998; Runyan et al., 2008). These factors are likely to have important relationships with young workers' behavior in organizations (Breslin et al., 2007), and it is possible that, in the absence of these environmental factors in a model, the predictive power of injunctive safety norms may be limited. As Zohar and Luria (2003) note, it is important to understand the concurrent effects of multiple environmental factors.

\subsection{Implications for managers and policy makers}

We found that young workers who are regularly exposed to supervisors' and co-workers' injunctive safety norms reported less frequent work-related risk-taking, which in turn was associated with lower frequency of work injuries in the case of supervisory injunctive safety norms. Based on our data, our findings suggest that supervisors can encourage safe work behavior in many contexts, including formal meetings and training programs, as well as more informal one-on-one communications. This, in turn, may have a spillover effect on coworkers, who could encourage other employees to work safely.
Drawing on other research investigating injunctive norms and occupational health and safety, we can infer that it would be beneficial for managers to encourage proactive safety behaviors by, for example, being open to hearing young workers' opinions about safety hazards and the unacceptability of unsafe acts (Tucker and Turner, 2013), as this supervisory orientation has shown to be related to fewer workplace injuries (Tucker and Turner, 2015). Similarly, public injury prevention campaigns could also encourage parents to express their intolerance toward risk-taking behaviors in the workplace, particularly when discussing transitions to different workplaces. We encourage educators and policy-makers to further investigate the linkage between specific safety-focused programs in school curricula and work-related risktaking behavior and consider which sources of encouragement would be most effective at influencing behavior. Such campaigns may ultimately lead to a decrease in the relatively high rate of workplace injuries among young workers; however, relative to other sources of social influence, the current study suggests the role of teachers is negligible.

\section{Conclusion}

To decrease the incidence of young worker risk-taking behavior and, by extension, injuries of this particular working population, it is important to understand which sources of injunctive safety norms may be the most salient to this vulnerable group. In a large sample of young workers, we found that young workers who are regularly exposed to supervisors', co-workers', and parents' injunctive safety norms reported fewer work injuries via less frequent work-related risk-taking, that young workers who are regularly exposed to friends' injunctive safety norms reported more work injuries via more frequent work-related risktaking, that siblings' injunctive safety norms were related to fewer work injuries (the mechanism by which remains unclear), and that teachers by comparison seemed to play a relatively limited role in predicting either work-related risk-taking or work injuries.

\section{Acknowledgements}

We thank Stephen Brisee, Paul Kells, Corey Pocaluyko, and Parachute Canada for supporting this project, and Terry Beehr, Steve Granger, Yueng-Hsiang (Emily) Huang, Michael Siegrist, and Bob Sinclair for comments on earlier drafts of this paper. This research did not receive any specific grant from funding agencies in the public, commercial, or not-for-profit sectors. We presented earlier versions of this paper at the 11th European Academy of Occupational Health Psychology conference, London, UK, and at the 5th Biennial Conference of Work, Well-being, and Performance, Sheffield, UK

\section{References}

Abelson, R.P., 1985. A variance explanation paradox: when a little is a lot. Psychol. Bull. 97 (1), 129-133. http://dx.doi.org/10.1037/0033-2909.97.1.129.

Ajzen, I., 1991. The theory of planned behavior. Organ. Behav. Hum. Decis. Process 50 (2), 179-211.

Armitage, C.J., Conner, M., 2001. Efficacy of the theory of planned behaviour: a metaanalytic review. Br. J. Soc. Psychol. 40 (4), 471-499.

Barling, J., Loughlin, C., Kelloway, E.K., 2002. Development and test of a model linking safety-specific transformational leadership and occupational safety. J. Appl. Psychol. 87 (3), 488-496. http://dx.doi.org/10.1037//0021-9010.87.3.488.

Bergkvist, L., Rossiter, J.R., 2007. The predictive validity of multiple-item versus singleitem measures of the same constructs. J. Mark. Res. 44 (2), 175-184.

Breslin, F.C., Smith, P., 2005. Age-related differences in work injuries: a multivariate, population-based study. Am. J. Ind. Med. 48 (1), 50-56.

Breslin, F.C., Koehoorn, M., Smith, P., Manno, M., 2003. Age related differences in work injuries and permanent impairment: a comparison of workers' compensation claims among adolescents, young adults, and adults. Occup. Environ. Med. 60 (9), e10.

Breslin, F.C., Smith, P., Mustard, C., Zhao, R., 2006. Young people and work injuries: an examination of jurisdictional variation within Canada. Inj. Prev. 12 (2), 105-110. http://dx.doi.org/10.1136/ip.2005.009449.

Breslin, F.C., Day, D., Tompa, E., Irvin, E., Bhattacharyya, S., Clarke, J., Wang, A., 2007. Non-agricultural work injuries among youth: a systematic review. Am. J. Prev. Med. 32 (2), 151-162. 
Breslin, F.C., Morassaei, S., Wood, M., Mustard, C.A., 2011. Assessing occupational health and safety of young workers who use youth employment centers. Am. J. Ind. Med. 54 (4), 325-337.

Breslin, F.C., 2008. Educational status and work injury among young people: refining the targeting of prevention resources. Can. J. Public Heal. Can. 121-124 Santee Publique.

Brondino, M., Silva, S.A., Pasini, M., 2012. Multilevel approach to organizational and group safety climate and safety performance: co-workers as the missing link. Saf. Sci. 50 (9), 1847-1856.

Brown, B.B., Clasen, D.R., Eicher, S.A., 1986. Perceptions of peer pressure, peer conformity dispositions, and self-reported behavior among adolescents. Dev. Psychol. 22 (4), 521-530.

Byrnes, J.P., Miller, D.C., Schafer, W.D., 1999. Gender differences in risk taking: a metaanalysis. Psychol. Bull. 125 (3), 367-383.

Christensen, S., Morrongiello, B.A., 1997. The influence of peers on children's judgments about engaging in behaviors that threaten their safety. J. Appl. Dev. Psychol. 18 (4), 547-562.

Christian, M.S., Bradley, J.C., Wallace, J.C., Burke, M.J., 2009. Workplace safety: a metaanalysis of the roles of person and situation factors. J. Appl. Psychol. 94 (5), 1103-1127. http://dx.doi.org/10.1037/a0016172.

Cialdini, R.B., Reno, R.R., Kallgren, C.A., 1990. A focus theory of normative conduct: recycling the concept of norms to reduce littering in public places. J. Pers. Soc. Psychol. 58 (6), 1015-1026.

Cialdini, R.B., Kallgren, C.A., Reno, R.R., 1991. A focus theory of normative conduct: a theoretical refinement and reevaluation of the role of norms in human behavior. Adv. Exp. Soc. Psychol. 24 (20), 1-243.

Clarke, S., 2006. The relationship between safety climate and safety performance: a metaanalytic review. J. Occup. Health Psychol. 11 (4), 315-327.

Clarke, S., 2012. Safety leadership: a meta-analytic review of transformational and transactional leadership styles as antecedents of safety behaviours. J. Occup. Organ. Psychol. 86 (1), 22-49.

Deutsch, M., Gerard, H.B., 1955. A study of normative and informational social influences upon individual judgment. J. Abnorm. Soc. Psychol. 51 (3), 629-636.

Dong, X.S., Wang, X., Largay, J.A., Sokas, R., 2016. Economic consequences of workplace injuries in the United States: findings from the national longitudinal survey of youth (NLSY79). Am. J. Ind. Med. 59, 106-118.

Elek, E., Miller-Day, M., Hecht, M.L., 2006. Influences of personal, injunctive, and descriptive norms on early adolescent substance use. J. Drug Issues 36 (1), 147-172.

Evans, D., Norman, P., 1998. Understanding pedestrians' road crossing decisions: an application of the theory of planned behaviour. Health Educ. Res. 13 (4), 481-489.

Frone, M.R., 1998. Predictors of work injuries among employed adolescents. J. Appl. Psychol. 83 (4), 565-576.

Fuchs, C., Diamantopoulos, A., 2009. Using single-item measures for construct measurement in management research. Betriebswirtschaft 69 (2), 195-210.

Fugas, C.S., Meliá, J.L., Silva, S.A., 2011. The is and the ought: how do perceived social norms influence safety behaviors at work? J. Occup. Health Psychol. 16 (1), 67-79. http://dx.doi.org/10.1037/a0021731.

Fugas, C.S., Silva, S.A., Meliá, J.L., 2013. Profiling safety behaviors: exploration of the sociocognitive variables that best discriminate between different behavioral patterns. Risk Anal. 33 (5), 838-850. http://dx.doi.org/10.1111/j.1539-6924.2012.01913.x.

Galizzi, M., Tempesti, T., 2015. Workers' risk tolerance and occupational injuries. Risk Anal. 35 (10), 1858-1875. http://dx.doi.org/10.1111/risa.12364.

Gray, M.R., Steinberg, L., 1999. Unpacking authoritative parenting: reassessing a multidimensional construct. J. Marriage Fam. 61, 574-587.

Hair, J.F.J., Anderson, R.E., Tatham, R.L., Black, W.C., 1995. Multivariate Data Analysis, 3rd ed. Macmillan, New York, NY.

Harris, J.R., 1995. Where is the child's environment? A group socialization theory of development. Psychol. Rev. 102 (3), 458-489.

Howe, N., Strauss, W., 2007. Helicopter parents in the workplace. Synd. Res. Proj. NGenera.

Jiang, L., Yu, G., Li, Y., Li, F., 2010. Perceived colleagues' safety knowledge/behavior and safety performance: safety climate as a moderator in a multilevel study. Accid. Anal. Prev. 42 (5), 1468-1476. http://dx.doi.org/10.1016/j.aap.2009.08.017.

Lamb, M.E., Sutton-Smith, B., 2014. Sibling relationships: their nature and significance across the lifespan. Psychology Press.

Leonardi-Bee, J., Jere, M.L., Britton, J., 2011. Exposure to parental and sibling smoking and the risk of smoking uptake in childhood and adolescence: a systematic review and meta-analysis. Thorax 66, 847-855.

Linker, D., Miller, M.E., Freeman, K.S., Burbacher, T., 2005. Health and safety awareness for working teens: developing a successful, statewide program for educating teen workers. Fam. Community Health 28 (3), 225-238.

Marsden, P.V., Campbell, K.E., 1984. Measuring tie strength. Soc. Forces 63 (2), 482-501.

Maxwell, S.E., Cole, D.A., 2007. Bias in cross-sectional analyses of longitudinal mediation. Psychol. Methods 12 (1), 23-44.

Miller, M.E., Handelman, E., Lewis, C., 2007. Protecting young workers: coordinated strategies help to raise safety awareness. Prof. Saf. 52 (6), 38-45.

Morrongiello, B.A., Bradley, M.D., 1997. Sibling power: influence of older siblings' per suasive appeals on younger siblings' judgements about risk taking behaviours. Inj. Prev. 3 (1), 23-28.

Morrongiello, B.A., Corbett, M., Bellissimo, A., 2008. Do as I say, not as I do": Family influences on children's safety and risk behaviors. Health Psychol. 27 (4), 498-503. http://dx.doi.org/10.1037/0278-6133.27.4.498.

Mullen, J., 2004. Investigating factors that influence individual safety behavior at work. J. Safety Res. 35 (3), 275-285. http://dx.doi.org/10.1016/j.jsr.2004.03.011.

Muthén, L.K., Muthén, B.O., 2010. Mplus User's Guide: Statistical Analysis with Latent Bariables: User's Guide. Muthén \& Muthén.

Neighbors, C., O'Connor, R.M., Lewis, M.A., Chawla, N., Lee, C.M., Fossos, N., 2008. The relative impact of injunctive norms on college student drinking: the role of reference group. Psychol. Addict. Behav. 22 (4), 576-581. http://dx.doi.org/10.1037/ a0013043.

Neufeld, S., Wright, S.M., Gaut, J., 2002. Not raising a bubble kid: farm parents' attitudes and practices regarding the employment, training and supervision of their children. J. Rural Health 18 (1), 57-66.

O'Brien, R.M., 2007. A caution regarding rules of thumb for variance inflation factors. Qual. Quant. 41 (5), 673-690.

O'Callaghan, F.V., Nausbaum, S., 2006. Predicting bicycle helmet wearing intentions and behavior among adolescents. J. Safety Res. 37 (5), 425-431. http://dx.doi.org/10. 1016/j.jsr.2006.08.001.

Olds, R.S., Thombs, D.L., Tomasek, J.R., 2005. Relations between normative beliefs and initiation intentions toward cigarette, alcohol and marijuana. J. Adolesc. Health 37 (1), 75.

Parachute Canada, 2013. Passport to Safety [WWW Document]. https://passporttosafety.parachutecanada.org/(Accessed 25 November 2013).

Parker, S.K., Axtell, C.M., Turner, N., 2001. Designing a safer workplace: importance of job autonomy, communication quality, and supportive supervisors. J. Occup. Health Psychol. 6 (3), 211-228. http://dx.doi.org/10.1037//1076-8998.6.3.211.

Pisaniello, D.L., Stewart, S.K., Jahan, N., Pisaniello, S.L., Winefield, H., Braunack-Mayer, A., 2013. The role of high schools in introductory occupational safety education - Teacher perspectives on effectiveness. Saf. Sci. 55, 53-61. http://dx.doi.org/10. 1016/j.ssci.2012.12.011.

Preacher, K.J., Zyphur, M.J., Zhang, Z., 2010. A general multilevel SEM framework for assessing multilevel mediation. Psychol. Methods 15 (3), 209-233.

Raffaelli, M., Crockett, L.J., 2003. Sexual risk taking in adolescence: the role of selfregulation and attraction to risk. Dev. Psychol. 39 (6), 1036-1046.

Reed, D.B., Westneat, S.C., Kidd, P., 2003. Observation study of students who completed a high school agricultural safety education program. J. Agric. Saf. Health 9 (4), 275-283.

Rimal, R.N., Real, K., 2003. Understanding the influence of perceived norms on behaviors. Commun. Theory 13 (2), 184-203.

Robins, R.W., Hendin, H.M., Trzesniewski, K.H., 2001. Measuring global self-esteem: construct validation of a single-item measure and the rosenberg self-esteem scale. Pers. Soc. Psychol. Bull. 27 (2), 151-161. http://dx.doi.org/10.1177/ 0146167201272002

Runyan, C.W., Vladutiu, C.J., Rauscher, K.J., Schulman, M., 2008. Teen workers' exposures to occupational hazards and use of personal protective equipment. Am. J. Ind. Med. 51 (10), 735-740. http://dx.doi.org/10.1002/ajim.20624.

Runyan, C.W., Schulman, M., Santo, J.D., Bowling, J.M., Agans, R., 2009. Attitudes and beliefs about adolescent work and workplace safety among parents of working adolescents. J. Adolesc. Health 44 (4), 349-355. http://dx.doi.org/10.1016/j.jadohealth. 2008.08.009.

Runyan, C.W., Vladutiu, C.J., Schulman, M.D., Rauscher, K.J., 2011. Parental involvement with their working teens. J. Adolesc. Health 49 (1), 84-86.

Runyan, C.W., Lewko, J., Rauscher, K., Castillo, D., Brandspigel, S., 2013. Health and safety of young workers. In: Proceedings of a US and Canadian Series of Symposia. National Institute for Occupational Safety and Health (NIOSH). Centers for Disease Control and Prevention Atlanta,GE.

Ryan, R.M., Stiller, J.D., Lynch, J.H., 1994. Representations of relationships to teachers, parents, and friends as predictors of academic motivation and self-esteem. J. Early Adolesc. 14 (2), 226-249.

Salminen, S., 2004. Have young workers more injuries than older ones?: An international literature review. J. Safety Res. 35 (5), 513-521.

Satorra, A., Bentler, P.M., 2010. Ensuring positiveness of the scaled difference chi-square test statistic. Psychometrika 75 (2), 243-248.

Savin-Williams, R.C., Berndt, T.J., 1990. Friendship and peer relations. In: Elliot, G.R. (Ed.), At the Threshold: The Developing Adolescent. Harvard University Press, Cambridge, MA, pp. 277-307.

Simons-Morton, B.G., Ouimet, M.C., Zhang, Z., Klauer, S.E., Lee, S.E., Wang, J., Chen, R. Albert, P., Dingus, T.A., 2011. The effect of passengers and risk-taking friends on risky driving and crashes/near crashes among novice teenagers. J. Adolesc. Health 49 (6), 587-593.

Smith, T.D., DeJoy, D.M., 2012. Occupational injury in America: an analysis of risk fac tors using data from the General Social Survey (GSS). J. Safety Res. 43 (1), 67-74.

Smith, P.M., 2015. Workplace climate, employee actions, work injury and structural equation modelling. Occup. Environ. Med. 72 (7), 465-466. http://dx doi.org/10. 1136/oemed-2015-102850. oemed-2015-102850.

Steinberg, L., 2001. We know some things: parent-adolescent relationships in retrospect and prospect. J. Res. Adolesc. 11 (1), 1-19.

Tucker, S., Turner, N., 2011. Young worker safety behaviors: development and validation of measures. Accid. Anal. Prev. 43 (1), 165-175. http://dx.doi.org/10.1016/j.aap. 2010.08.006.

Tucker, S., Turner, N., 2013. Waiting for safety: responses by young Canadian workers to unsafe work. J. Safety Res. 45, 103-110.

Tucker, S., Turner, N., 2015. Sometimes it hurts when supervisors don't listen: the antecedents and consequences of safety voice among young workers. J. Occup. Health Psychol. 20 (1), 72-81. http://dx.doi.org/10.1037/a0037756.

Tucker, S., Chmiel, N., Turner, N., Hershcovis, M.S., Stride, C.B., 2008. Perceived organizational support for safety and employee safety voice: the mediating role of coworker support for safety. J. Occup. Health Psychol. 13 (4), 319-330. http://dx.doi. org/10.1037/1076-8998.13.4.319.

Tucker, S., Diekrager, D., Turner, N., Kelloway, K.E., 2014. Work-related injury underreporting among young workers: Prevalence, gender differences, and explanations fo underreporting. J. Safety Res. 50, 67-73.

Tucker, S., Pek, S., Morrish, J., Ruf, M., 2015. Prevalence of texting while driving and 
other risky driving behaviors among young people in Ontario, Canada: Evidence from 2012 and 2014. Accid. Anal. Prev. 84, 144-152.

Turner, N., Chmiel, N., Hershcovis, M.S., Walls, M., 2010. Life on the line: job demands, perceived co-worker support for safety, and hazardous work events. J. Occup. Health Psychol. 15 (4), 482-493.

Turner, N., Tucker, S., Kelloway, E.K., 2015. Prevalence and demographic differences in microaccidents and safety behaviors among young workers in Canada. J. Safety Res. 53, 39-43.

Tyler, K.A., Stone, R.T., Bersani, B., 2006. Examining the changing influence of predictors on adolescent alcohol misuse. J. Child Adolesc. Subst. Abuse 16 (2), 95-114.

Tzelgov, J., Henik, A., 1991. Suppression situations in psychological research: definitions, implications, and applications. Psychol. Bull. 109 (3), 524-536.

Urberg, K.A., Değirmencioğlu, S.M., Pilgrim, C., 1997. Close friend and group influence on adolescent cigarette smoking and alcohol use. Dev. Psychol. 33 (5), 834-844.

Voisine, S., Parsai, M., Marsiglia, F., Kulis, S., Nieri, T., 2008. Effects of parental monitoring, permissiveness, and injunctive norms on substance use among Mexican and Mexican American adolescents. Fam. Soc. J. Contemp. Soc. Serv. 89 (2), 264-273.

Vrieze, S.I., 2012. Model selection and psychological theory: a discussion of the differences between the Akaike information criterion (AIC) and the Bayesian information criterion (BIC). Psychol. Methods 17 (2), 228-243.

Wanous, J.P., Reichers, A.E., Hudy, M.J., 1997. Overall job satisfaction: how good are single-item measures? J. Appl. Psychol. 82 (2), 247-252.

Webb, M., Ronan, K.R., 2014. Interactive hazards education program for youth in a low SES community: a quasi-experimental pilot study. Risk Anal. 34 (10), 1882-1893. http://dx.doi.org/10.1111/risa.12217.

Westaby, J.D., Lee, B.C., 2003. Antecedents of injury among youth in agricultural settings: a longitudinal examination of safety consciousness, dangerous risk taking, and safety knowledge. J. Safety Res. 34 (3), 227-240. http://dx.doi.org/10.1016/S0022 4375(03)00030-6.

Westaby, J.D., Lowe, J.K., 2005. Risk-taking orientation and injury among youth workers: examining the social influence of supervisors, coworkers, and parents. J. Appl. Psychol. 90 (5), 1027-1035. http://dx.doi.org/10.1037/0021-9010.90.5.1027.

WorksafeBC, 2015. Statistics for Young Workers [WWW Document]. https://www2 worksafebc.com/topics/youngworker/Statistics.asp (Accessed 10 January 2015).

Yagil, D., Luria, G., 2010. Friends in need: the protective effect of social relationships under low-safety climate. Group Organ. Manag. 35 (6), 727-750. http://dx.doi.org/ 10.1177/1059601110390936.

Zohar, D., Luria, G., 2003. The use of supervisory practices as leverage to improve safety behavior: a cross-level intervention model. J. Safety Res. 34 (5), 567-577.

Zohar, D., 1980. Safety climate in industrial organizations: theoretical and applied im plications. J. Appl. Psychol. 65 (1), 96-102.

Zohar, D., 2010. Thirty years of safety climate research: reflections and future directions. Accid. Anal. Prev. 42 (5), 1517-1522.

Zohar, D., Polachek, T., 2014. Discourse-based intervention for modifying supervisory communication as leverage for safety climate and performance improvement: a randomized field study. J. Appl. Psychol. 99 (1), 113-124. http://dx.doi.org/10 1037/a0034096. 